\title{
In vivo absorption characteristics in 10 classes of bloom-forming phytoplankton: taxonomic characteristics and responses to photoadaptation by means of discriminant and HPLC analysis
}

\author{
Geir Johnsen ${ }^{1}$, Oddgeir Samset ${ }^{2}$, Lois Granskog ${ }^{1}{ }^{,}$Egil Sakshaug ${ }^{1}$ \\ ${ }^{1}$ Trondhjem Biological Station, The Museum, University of Trondheim, Bynesveien 46, N-7018 Trondheim, Norway \\ ${ }^{2}$ SINTEF Industrial Mathematics, NTH, N-7034 Trondheim, Norway
}

\begin{abstract}
The spectral light absorption characteristics $(400$ to $700 \mathrm{~nm}$ ) of 10 main classes, covering 31 species, of bloom-forming phytoplankton (diatoms, dinoflagellates, prymnesiophytes, euglenophytes, prasinophytes, raphidophytes, cryptophytes, chlorophytes, chrysophytes and cyanobacteria) have been examined. The survey is based on in vivo chlorophyll (chl) a-specific light absorption spectra [ ${ }^{\circ} a_{c}(\lambda), 400$ to $700 \mathrm{~nm}$ ] of low- and high-light adapted monocultures grown in the laboratory. Pigments were isolated by means of high-performance liquid chromatography (HPLC) to obtain visible spectra of isolated pigments to identify peaks and shoulders of the in vivo absorption spectra. A total of $217^{\circ} a_{c}(\lambda)$ spectra were $\log$-transformed and normalized at $675 \mathrm{~nm}\left[a_{\log }(\lambda)\right]$ to minimize photoadaptational effects on the spectral characteristics due to differences in pigment composition and the package effect. These $a_{\text {log }}(\lambda)$ spectra were analyzed by stepwise discriminant analysis to determine sets of optimum wavelengths for classification. Discrimination and classification were most effective when lowand high-light adapted phytoplankton were grouped separately. A set of only 3 wavelengths $(481,535$, $649 \mathrm{~nm}$ ) chosen on the basis of discriminant analysis classified, according to the jackknife technique, $93 \%$ of the $a_{\log }(\lambda)$ spectra. By using combinations of $4(481,535,586,649 \mathrm{~nm})$ or $5(481,535,586,628$, $649 \mathrm{~nm}$ ) chosen wavelengths, 97 to $99 \%$ of the spectra were classified correctly. For pooled data (lowand high-light adapted cells), 60 to $86 \%$ of the spectra were correctly identified using a combination of 3 to 5 selected wavelengths, indicating that variations due to photoadaptation were not entirely removed by log-transforming and scaling of the spectra at $675 \mathrm{~nm}$. By using the above combination of 3 wavelengths, 4 main groups of phytoplankton were clearly separated, depending mainly on their accessory chlorophylls, i.e. chl $b$ (prasinophytes, euglenophytes, chlorophytes), chl $c_{1}$ and/or $c_{2}$ (diatoms, dinoflagellates, prymnesiophytes, chrysophytes, raphidophytes, cryptophytes), chl $c_{3}$ (toxic prymnesiophytes and dinoflagellates) and no accessory chlorophylls (cyanobacteria). The wavelengths employed here correspond to the peaks and shoulders of the in vivo absorption spectra. We conclude that different phytoplankton classes may be identified during blooms on the basis of in situ bio-optical measurements at 3 to 5 appropriately chosen wavelengths
\end{abstract}

KEY WORDS: Bio-optical taxonomy - In vivo light absorption · Pigment composition - Photoadaptation Phytoplankton classes · Discriminant analysis

\section{INTRODUCTION}

Marine phytoplankton have evolved a large variety of light-harvesting pigment systems. The 3 main pigment groups that determine the bio-optical properties are the chlorophylls, the carotenoids and the phycobiliproteins (Rowan 1989). Identification of phytoplankton on the basis of in vivo light absorption spec- tra thus depends on the pigment composition of the cells, as modified by variations in the photoadaptational response, and how many wavelengths are measured (cf. SooHoo et al. 1986, Bidigare et al. 1987. 1989a, 1990a, b, Sathyendranath et al. 1987, Hoepffner \& Sathyendranath 1991)

Different species of photosynthetic phytoplankton contain different accessory chlorophylls in addition to 
the ubiquitous chlorophyll (chl) a. Whereas chl a exhibits in vivo absorption maxima at 440 and $675 \mathrm{~nm}$, chl $b$ exhibits peaks at ca 470 and $650 \mathrm{~nm}$ (Bidigare et al. 1990b). Chl $c$ represents a mixture of slightly spectrally distinct components: $\mathrm{chl} c_{1}$, chl $c_{21}$ chl $c_{3}$ and magnesium 2,4-divinyl phaeoporphyrin $a_{5}$ monomethyl ester (Mg-D). These have in vivo absorption maxima at approximately 460 to 470,586 and $635 \mathrm{~nm}$ (Rowan 1989, Bidigare et al. 1990a, Johnsen et al. 1992, Johnsen \& Sakshaug 1993).

The carotenoids of eukaryotic phytoplankton and cyanobacteria represent more than 100 different pigments which absorb mainly in the blue to green parts of the visible spectrum (Straub 1987, Bjørnland \& Liaaen-Jensen 1989, Rowan 1989). The most important light-harvesting carotenoids are fucoxanthin and its $19^{\prime}$-acyloxy-derivatives as well as peridinin; the latter being specific to the majority of dinoflagellates (cf. Liaaen-Jensen 1978, Jeffrey 1980, 1989, Bjørnland \& Liaaen-Jensen 1989, Rowan 1989).

The 4 major types of phycobiliproteins are phycocyanin, phycoerythrin, allophycocyanin, and phycoerythrocyanin (the major light-harvesting pigments in the cyanobacteria and cryptophytes) (Rowan 1989).

In most cases the major in vivo absorption signature in blue (400 to $500 \mathrm{~nm}$ ), and especially in red (580 to $700 \mathrm{~nm}$ ), is caused by the chlorophylls (chl $a, b$ and $c$; Bidigare et al. 1990a, b). The major light-harvesting carotenoids, i.e. the fucoxanthins and the 19'-acyloxyfucoxanthins together with peridinin and prasinoxanthin absorb in vivo mainly at 450 to $550 \mathrm{~nm}$ (Prézelin \& Boczar 1986, Bidigare et al. 1987, 1990b, Sathyendranath et al. 1987, Johnsen et al, 1992). Phycobiliprotein-dominated pigment systems of many cyanobacteria and cryptophytes absorb green to orange light (480 to $600 \mathrm{~nm}$ ) efficiently (Prézelin \& Boczar 1986, Bidigare et al. 1987, 1989b).

As more is learned about the molecular basis for the bio-optical differences between classes of phytoplankton, spectral characteristics of the different types of pigment-proteins and their respective pigment composition can form a useful basis for the determination of the phytoplankton composition in natural waters (Kirk 1983, Prézelin \& Boczar 1986, Rowan 1989). With this respect, instruments for in situ measurements must be calibrated against data for phytoplankton grown under controlled conditions in the laboratory to understand how environmental factors affect the in vivo absorption characteristics in different phytoplankton classes. We consider here only the effect of light, i.e. photoadaptive effects and sets of wavelength optimized for identification of spectra, although temperature and nutrient effects also play a role.

Our survey covers 31 species of important toxic and non-toxic bloom-forming phytoplankton, representing
10 phytoplankton classes, grown under low- and highlight conditions. The major objective was to determine sets of wavelengths that highlight, as accurately as possible, the bio-optical differences between light absorption spectra and, thus, the species.

In order to distinguish species-specific spectral in vivo absorption signatures, we have used discriminant analysis, a multivariate statistical technique (Mardia et al. 1979, Anderson 1984, Krzanowski 1988). This technique separates distinct sets of observations and classifies new observations relative to the previously defined groups. The predictions obtained from the discriminant analysis has formed the basis for selection of convenient sets of wavelengths, for which the appropriateness can be checked independently by the use of jackknife technique. Such information derived from laboratory cultures may be of value for the identification of different phytoplankton groups in situ on the basis of data from multi-wavelength transmissometers connected to buoys, as a supplement or an alternative to the traditional use of microscopy.

\section{MATERIAL AND METHODS}

Cultures. The different isolates were obtained from the culture collection of Trondhjem Biological Station, University of Oslo, Plymouth Culture Collection and the Provasoli-Guillard Centre for Culture of Marine Phytoplankton (Table 1). The cultures were grown in f/2 medium (Guillard \& Ryther 1962), with addition of silicate (diatoms), soil extract (euglenophytes and cyanobacteria) and selenium (prymnesiophytes) at $15^{\circ} \mathrm{C}$ (except $0^{\circ} \mathrm{C}$ for Synedra hyperborea and $20^{\circ} \mathrm{C}$ for Gyrodinium aureolum and Gymnodinium galatheanum) and a salinity of $33 \%$ (Table 1). Scalar irradiance $\left(E_{0}, 400\right.$ to $\left.700 \mathrm{~nm}, \mathrm{PAR}\right)$ was measured inside the culture flasks filled with distilled water by means of a QSL-100 quantum sensor (Biospherical Instruments). The cultures were grown in cool-white fluorescent light with similar spectral output (Philips TLD 18W/95 and TL 40W/55). The light regimes for the different cultures were as follows; day lengths of 12 or $24 \mathrm{~h}$ with low light ( $\mathrm{LL}, 15$ to $75 \mu \mathrm{mol} \mathrm{m}^{-2} \mathrm{~s}^{-1}$ ) and high light ( $\mathrm{HL}$, 170 to $500 \mu \mathrm{mol} \mathrm{m}{ }^{-2} \mathrm{~s}^{-1}$ i Table 1). The cultures were allowed to adapt to the experimental light regime for 6 to 12 generations before sampling was carried out during the exponential growth phase.

Pigments. Subsamples were concentrated on Whatman GF/C or GF/F (small cells) glass-fibre filters at $50 \mathrm{mb}$ differential pressure and immediately extracted at 0 to $4{ }^{\circ} \mathrm{C}$ for $20 \mathrm{~h}$ (Johnsen \& Sakshaug 1993) using a mixture of methanol and acetone $(3: 7, \mathrm{vol}: \mathrm{vol})$ (Hertzberg \& Liaaen-Jensen 1966). The extracts were refiltered through a Whatman GF/C or GF/F filter 
Table 1 . Overview of the 10 classes of phytoplankton (31 species) grown under high light (170 to $\left.500 \mu \mathrm{mol} \mathrm{m}^{-2} \mathrm{~s}^{-1}\right)$ and low light $\left(15\right.$ to $\left.75 \mu \mathrm{mol} \mathrm{m} \mathrm{m}^{-2} \mathrm{~s}^{-1}\right)$ used in this survey for measuring spectral in vivo absorption characteristics $[a \log (\lambda)]$. Note: $M, V, 1,3$ and 4 were only grown in low light. Isolate sources are TBS: Trondhjem Biological Station; UO: University of Oslo; PCC: Plymouth Culture Collection; P-G: Provasoli-Guillard Centre for Culture of Marine Phytoplankton

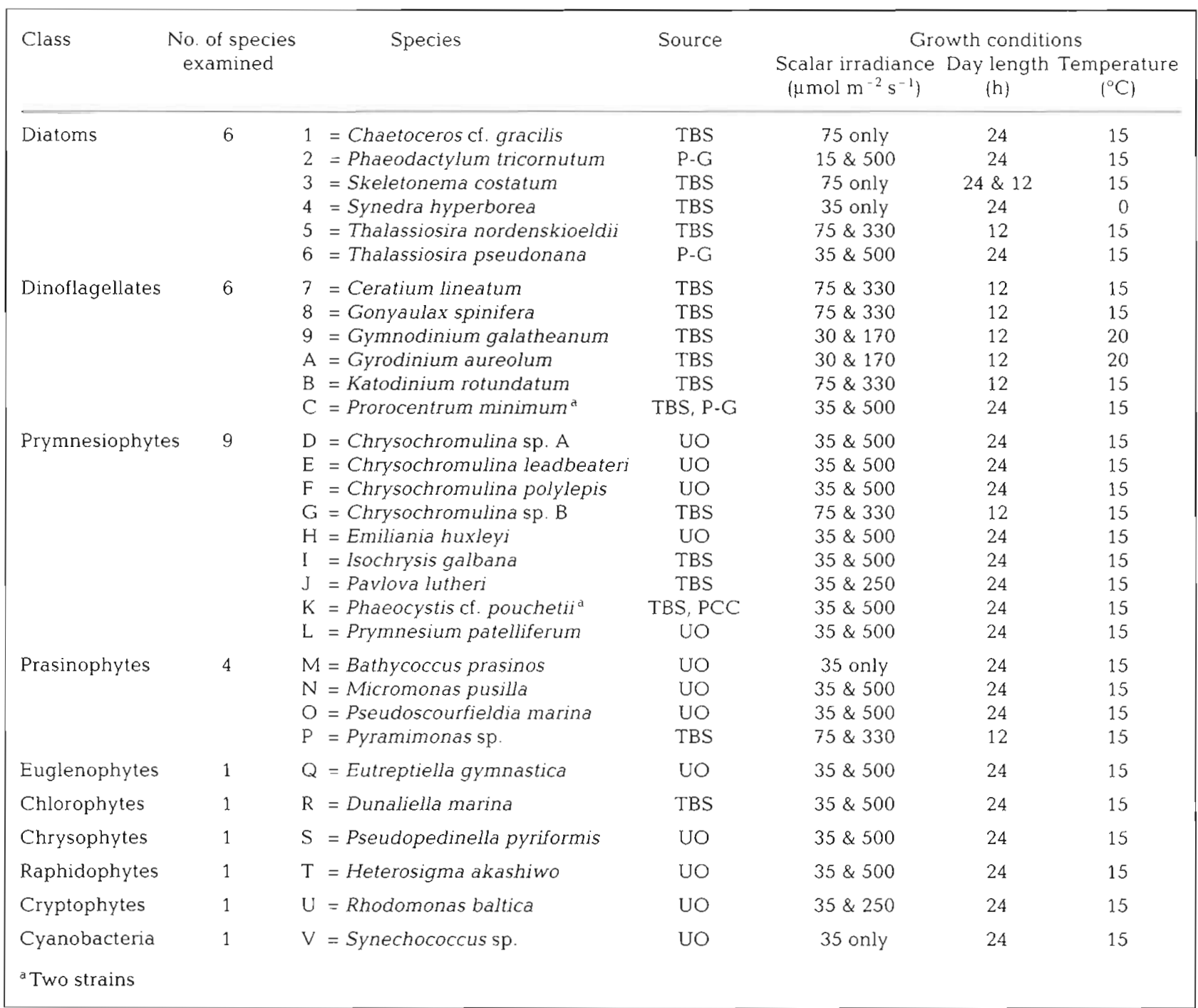

before analysis. Chl a concentration and purity were estimated spectrophotometrically together with HPLC (high-performance liquid chromatography) for normalizing of in vivo absorption spectra to chl a (Jeffrey \& Humprey 1975, Johnsen et al. 1992). Pigment analyses were carried out with a Merck \& Hitachi L-6200 HPLC equipped with a SPHERI-5 RP-18 reverse-phase C-18 column (Brownlee Labs $25 \mathrm{~cm} \times 4.6 \mathrm{~mm}, 5 \mu \mathrm{m}$ particles; Johnsen et al. 1992). Extracts of 50 to $100 \mu \mathrm{l}$ were injected into the HPLC and detection performed at $440 \mathrm{~nm}$ in a Hitachi Spectrophotometer Model U2000 fitted with a flow-through cell using the solvent system presented by Mantoura \& Llewellyn (1983). For spectral identification of isolated pigments, the HPLC pump was stopped at the maximum absorption peak and scanned from 350 to $800 \mathrm{~nm}$ at $0.5 \mathrm{~nm}$ intervals ('stop-flow technique'). Several authentic standards of pigments for identification and calibration of the HPLC were obtained from Chrysochromulina polylepis (Johnsen et al. 1992) and 3 species of dinoflagellates (Johnsen \& Sakshaug 1993). Standards of peridinin, neoxanthin, prasinoxanthin, alloxanthin, lutein, echinenone and $\alpha$-carotene (TLC-isolated) were donated by the Carotenoid Group at the Institute of Organic Chemistry, University of Trondheim-NTH. Other pigments obtained from the cultures used here were isolated and characterized by means of HPLC, using the stop-flow technique to measure spectral absorption (carotenoids and chlorophylls) and fluorescence excitation (chlorophylls only) characteristics (Johnsen \& 
tion peaks at 437,490 and $676 \mathrm{~nm}$, which correspond to chl a (in vivo peaks at 437 and $676 \mathrm{~nm}$; Prézelin \& Boczar 1986, Bidigare et al. 1990b) and diadinoxanthin (in vivo peaks at $490 \mathrm{~nm}$; G. Johnsen unpubl.), whereas shoulders at 415,460, 535, 585 and $630 \mathrm{~nm}$ are due mainly to absorption by chl a $(415 \mathrm{~nm}), \mathrm{chl} c_{1+2}$ together with fucoxanthin and diadinoxanthin $(460$ $\mathrm{nm}$ ), fucoxanthin (535 $\mathrm{nm}$ ) and, finally, chl $a$ and chl $c_{1+2}$ at 585 and $630 \mathrm{~nm}$ (cf. Prézelin \& Boczar 1986, Johnsen \& Sakshaug 1993; Figs. 1 \& 3, Table 2).

The in vivo spectral characteristics of phytoplankton (Figs. 1 \& 3) are also modified by the light regime (LL vs HL conditions). This variability, which is manifested both in the magnitude and the spectral shape of $a_{\log }(\lambda)$ is due to variations in pigment composition as well as the package effect (intracellular self shading; Fig. 3; Kirk 1983, Hoepffner \& Sathyendranath 1991). Photoadaptation-dependent variability thus may impede the identification of algal species on the basis of bio-optical characteristics. To minimize this problem, as well as to minimize the signals from chl a, we have logtransformed the spectra, scaled them at the red peak (675 nm) as well as discarded data for wavelengths $>652 \mathrm{~nm}$ in the mathematical treatments. The logtransformation enhanced, relatively, absorption in the information-rich region where small absorption peaks and shoulders are related to accessory pigments (580 to $652 \mathrm{~nm}$ ); the scaling at $675 \mathrm{~nm}$ minimized the package effect, while the exclusion of data for wavelengths $>652 \mathrm{~nm}$ removed some of the taxonomically irrelevant information from chl a without removing information from chl $b$ (red peak maximum at $650 \mathrm{~nm}$; Fig. 3, Table 2).

The original spectra $\left[{ }^{\circ} a_{c}(\lambda)\right]$ yielded information about absorption at no less than 300 wavelengths, and the corrected versions $\left[\alpha_{\log }(\lambda)\right]$ at 85 wavelengths. A crucial question in practical terms is how far the number of wavelengths can be reduced with no appreciable loss of taxonomically relevant information. The stepwise discriminant analysis selects wavelengths with high prediction success for the corrected spectra. This analysis indicates that a set of only 3 wavelengths, optimized for the classification of the spectra, can identify 93 to $97 \%$ of the spectra when they are grouped into LL and HL spectra, respectively. Two sets of either 3 or 5 wavelengths identified 72 and $92 \%$ of the spectra respectively, when pooled irrespective of photoadaptational status (Table 3 ). These results imply that few optimized wavelengths are necessary for identification; however, they also imply that our corrections did not remove variations due to photoadaptation entirely.

The sets of optimized wavelengths derived from discriminant analysis pose a practical problem in that they differ depending on whether the data sets are pooled

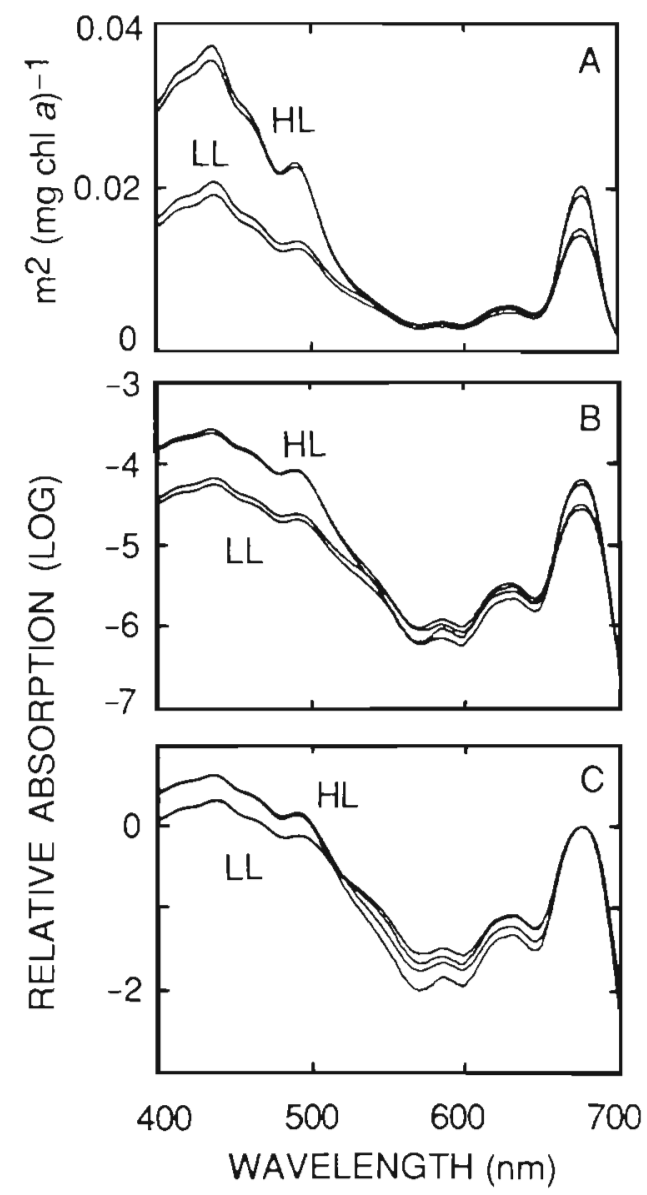

Fig. 1. In vivo absorption spectra from low-light (LL, $35 \mu \mathrm{mol}$ $\mathrm{m}^{-2} \mathrm{~s}^{-1}$ ) and high-light ( $\mathrm{HL}, 250 \mu \mathrm{mol} \mathrm{m} \mathrm{m}^{-2} \mathrm{~s}^{-1}$ ) adapted cells of the prymnesiophyte Pavlova lutheri grown at 24 h day length at $15^{\circ} \mathrm{C}$. (A) Chl a-specific absorption spectra, $1^{\circ} a_{c}(\lambda)$, $\mathrm{m}^{2} \mathrm{mg}^{-1} \mathrm{chl}$ a) of HL-and LL-adapted cells $(\mathrm{n}=2)$. (B) Same as (A), but log-transformed. (C) Same as (B), but scaled at $675 \mathrm{~nm}\left[a_{\log }(\lambda)\right]$

or treated separately as LL and HL sets (Table 3). To overcome this, sets appropriate for both pooled HL and LL spectra have to be employed. Noting that many of the wavelengths in Table 3 are close neighbours, thus yielding insignificantly different information (data not shown), we have chosen $649,628,586,535$ and $481 \mathrm{~nm}$ (the latter representing the range 475 to $493 \mathrm{~nm}$ ) and tested the relevance of sets of these wavelength combinations by means of the jackknife technique. These wavelengths represent approximately the in vivo absorption maxima of important accessory pigments (Table 2).

The jackknife technique shows that the sets of chosen wavelengths (Table 4) identify about the same percent of the transformed spectra as sets with a corresponding number of wavelengths derived from stepwise discriminant analysis, provided that the spectra are separated into LL and HL groups (93 to $99 \%$, 


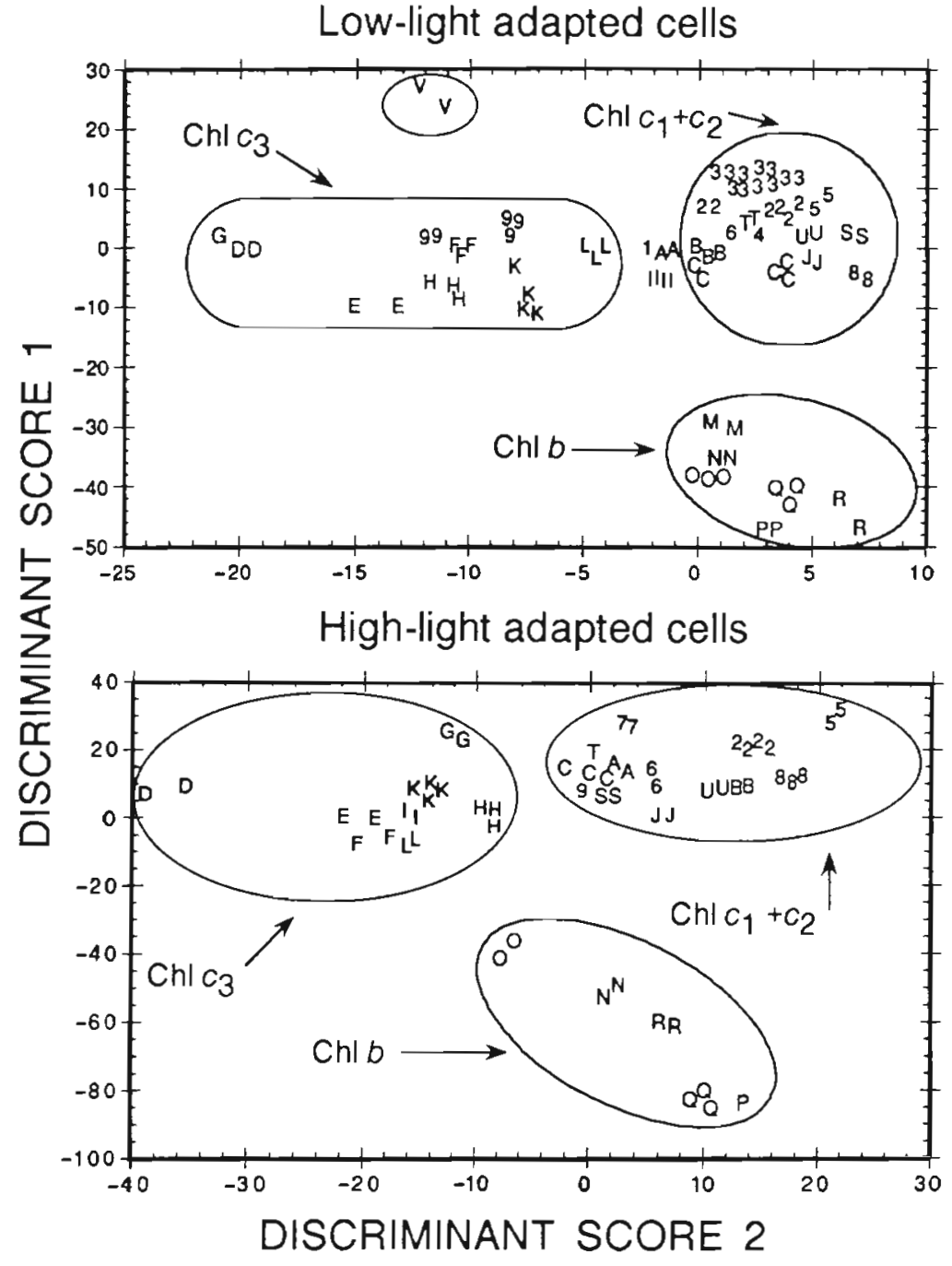

Fig. 2. Discriminant scores evaluated on $a_{\log }(\lambda)$ obtained from 10 classes of phytoplankton (31 species, 1 to 9 and $A$ to $V$; see Table 1) grown under low- and high-light conditions. Classification by means of 3 wavelengths: 481, 535 and $649 \mathrm{~nm}$. Classes: diatoms (1-6), dinoflagellates ( 7 to $9, A$ to $C$ ), prymnesiophytes (D to $L$ ), prasinophytes ( $M$ to $P$ ), euglenophytes $(Q)$. chlorophytes (R), chrysophytes (S), raphidophytes $(T)$, cryptophytes (U), and cyanobacteria (V). The figure is divided into 4 main zones: phytoplankton without accessory chlorophylls (Synechococcus sp. which did not grow in high light), chl $b$, chl $c_{3}$ and $c h l c_{1+2}$ containing phytoplankton. For further information, see Tables 1 to 4 . Note that these discriminant scores could be visualized in 3 dimensions, which would enhance the visual separation. Identical symbols denote replicates depending on whether 3,4 or 5 wavelengths are employed). The percent identified spectra on the basis of pooled sets, however, is somewhat lower for the sets of chosen wavelengths than for the sets of wavelengths derived from stepwise discriminant analysis. The stepwise discriminant analysis and the jackknife technique both agree that a set of 3 appropriate wavelengths is sufficient to identify the corrected spectra when they are grouped according to their photoadaptational status. For pooled data, a set of 5 wavelengths may be deemed sufficient, i.e. the set of 5 chosen wavelengths in Table 4 may identify $86 \%$ of the spectra correctly.

The species-specific differences in absorption can be visualized by the discrimination scores (the values of the linear combinations), using discriminant analysis. The set of the 3 chosen wavelengths which yielded the best discrimination, i.e. 481, 535 and $649 \mathrm{~nm}$, separates the $a_{\log }(\lambda)$ spectra into 4 main pigment-groups, depending on the type of accessory chlorophylls (chl $c_{1}$, chl $c_{2}$, chl $c_{3}, \mathrm{Mg}-\mathrm{D}$ and $\mathrm{chl} b_{i}$ Fig. 2). Group 1 repre- sents chl b-containing phytoplankton (prasinophytes, euglenophytes and chlorophytes); Group 2 chl $c_{1}$ and/or $C_{2}$-containing phytoplankton (diatoms, prymnesiophytes, chrysophytes, raphidophytes, dinoflagellates and cryptophytes); Group $3 \mathrm{chl} c_{3}$-containing phytoplankton (prymnesiophytes and dinoflagellates) which possess chl $c_{2}$ and sometimes chl $C_{1}$; and Group 4 is phytoplankton which lack accessory chlorophylls (cyanobacteria; Fig. 2, Table 2)

The 4 pigment groups can be further divided into several subgroups down to the species level, e.g the chl $b$-group can be divided into $\mathrm{Mg}-\mathrm{D}$ containing prasinophytes (which also contains prasinoxanthin; Fig. 2, species $M, N, O$; see Table 1 for species identification) and one for prasinophytes, chlorophytes and euglenophytes lacking Mg-D and prasinoxanthin (species $P, Q, R$ ). No large differences in discrimination were observed for LL-and HL-adapted species (Fig. 2). All the examined chl $c_{3}$-containing flagellates were grouped together by the discriminant analysis; these 
Fig. 3. (A) Mean log-transformed and red-peak $(675 \mathrm{~nm})$ scaled in vivo absorption spectra $\left[a_{\log }(\lambda)\right]$ in LL- and HL-adapted cells of 10 phytoplankton classes respectively. (B) Same as (A), but averaged for LL- and HL-adapted cells. Dotted lines: SD of the single observations. Species as in Table 1
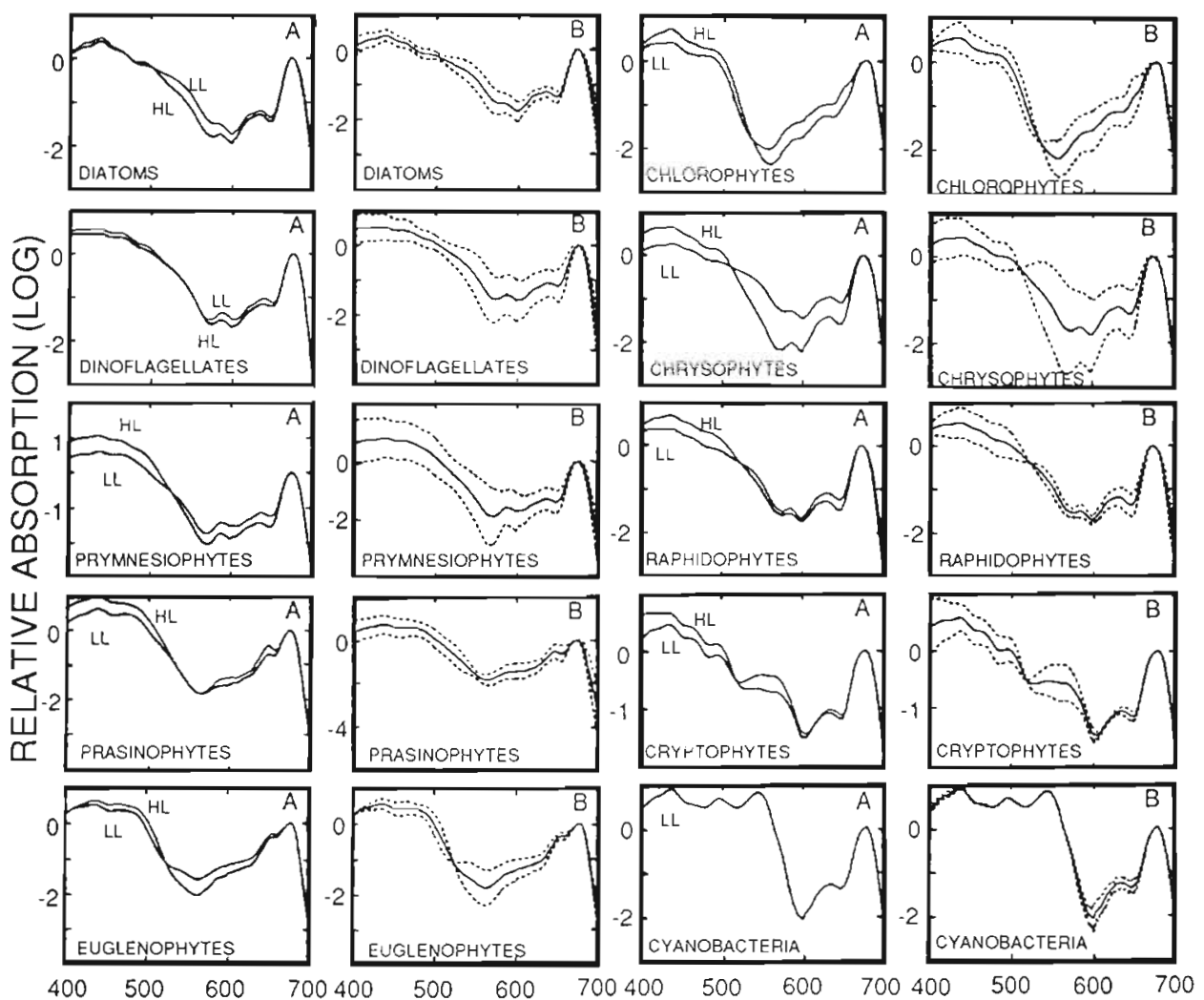

WAVELENGTH $(\mathrm{nm})$ are mainly toxic and bloom-forming species (Johnsen et al. 1992, Johnsen \& Sakshaug 1993). LL- and HLadapted cells of the chl $c_{3}$-containing dinoflagellates Gyrodinium aureolum and Gymnodinium galatheanum (Johnsen \& Sakshaug 1993) were grouped within or near the chl $\mathrm{C}_{3}$-containing prymnesiophytes, respectively. This indicates that their optical properties are

Table 3. Stepwise discriminant analysis. Identification of taxonomically important wavelengths based on $a_{\log }(\lambda)$ obtained from 31 species of phytoplankton. \% Pred: percent successful classifications. Data are grouped into low-light adapted cells (LL, 15 to $75 \mu \mathrm{mol} \mathrm{m} \mathrm{m}^{-2} \mathrm{~s}^{-1}$ ), high-light adapted cells (HL, 170 to $500 \mu \mathrm{mol} \mathrm{m}{ }^{-2} \mathrm{~s}^{-1}$ ) and pooled data ( $\mathrm{HL}+\mathrm{LL}$ ) by using up to 7 wavelengths $(\mathrm{nm})$ in combination

\begin{tabular}{|ccccccc|}
\hline $\begin{array}{c}\text { Cum. no. of } \\
\text { wavelengths } \\
\text { used }\end{array}$ & $\begin{array}{c}\mathrm{HL}+\mathrm{LL} \\
(\mathrm{n}=217) \\
\mathrm{nm} \% \text { Pred }\end{array}$ & $\begin{array}{c}\mathrm{LL} \\
(\mathrm{n}=147) \\
\mathrm{nm} \% \text { Pred }\end{array}$ & \begin{tabular}{c}
\multicolumn{1}{c|}{$\begin{array}{c}\mathrm{HL} \\
(\mathrm{n}=70)\end{array}$} \\
$\mathrm{nm} \%$ Pred
\end{tabular} \\
\hline 1 & 487 & 14 & 649 & 50 & 475 & 69 \\
2 & 652 & 47 & 628 & 74 & 652 & 96 \\
3 & 640 & 72 & 640 & 93 & 538 & 97 \\
4 & 544 & 86 & 535 & 99 & 640 & 100 \\
5 & 628 & 92 & 481 & 100 & 523 & 100 \\
6 & 586 & 98 & 517 & 100 & 628 & 100 \\
7 & 493 & 99 & 493 & 100 & 505 & 100 \\
\hline
\end{tabular}

similar to important chl $C_{3}$-containing prymnesiophyte genera such as Chrysochromulina, Prymnesium, Emiliania, and Phaeocystis (species A and 9 in Fig. 2; Jeffrey 1989, Johnsen et al. 1992, Johnsen \& Sakshaug 1993, G. Johnsen unpubl.). The chl $c_{1+2}$-containing Chaetoceros cf. gracilis (diatom) and Isochrysis galbana (prymnesiophyte lacking chl $c_{3}$ ) are also grouped at the border between chl $c_{3}$ and chl $C_{1+2}$-containing phytoplankton, indicating slightly different optical properties

Table 4. Jackknifing technique. Verification of the classification success of selected models (wavelengths) found by means of stepwise discriminant analysis (Table 3) using the jackknife technique. Data are grouped into low-light adapted cells (LL, 15 to $75 \mu \mathrm{mol} \mathrm{m} \mathrm{m}^{-2} \mathrm{~s}^{-1}$ ), high-light adapted cells (HL, 170 to $500 \mu \mathrm{mol} \mathrm{m} \mathrm{m}^{-2} \mathrm{~s}^{-1}$ ) and pooled data ( $\mathrm{HL}+\mathrm{LL}$ ) by using from 3 to 5 wavelengths $(\mathrm{nm})$ in combination

\begin{tabular}{|lccc|}
\hline Wavelengths (nm) & \multicolumn{3}{c|}{$\begin{array}{c}\text { \% Prediction } \\
(\mathrm{n}=217)\end{array}$} \\
& $(\mathrm{n}=147)$ & $\begin{array}{c}\mathrm{HL} \\
(\mathrm{n}=70)\end{array}$ \\
\hline $481,535,649$ & 60 & 93 & 93 \\
$481,535,586,649$ & 73 & 97 & 97 \\
$481,535,586,628,649$ & 86 & 99 & 97 \\
\hline
\end{tabular}




\section{DISCUSSION}

Our results demonstrate that in vivo light absorption characteristics and pigmentation agree closely, both in low light- and high light-adapted phytoplankton and that variations due to photoadaptation can be minimized albeit not entirely removed by our procedure involving log-transformation and scaling. However, 3 appropriately chosen wavelengths $(481,535,649 \mathrm{~nm})$ appear to be sufficient to identify groups, to some extent also species of phytoplankton. If we add 2 more wavelengths, i.e. $586 \mathrm{~nm}$ (indicating red peak absorption maxima of chl $c_{3}$ ) and $628 \mathrm{~nm}$ (indicates absorption peaks related to chl $c_{1+2}$; Johnsen et al. 1992 Johnsen \& Sakshaug 1993) the prediction success increases from 93 to $99 \%$ for sets grouped according to photoadaptional status (Table 4). The prediction success for pooled data increased more, from 60 to $86 \%$ (Table 4)

We found ca 20 major pigments which we consider as bio-optically taxonomically important (cf. Rowan 1989), in particular the accessory chlorophylls, which separate the 10 different phytoplankton classes optically into 4 main groups (1 toxic and 3 non-toxic Table 2, Figs. 2 \& 3).

Several techniques have been used to classify absorption characteristics in phytoplankton, i.e. spectral derivative analysis (Bidigare et al. 1989a), multiple regression (Sathyendranath et al. 1987) and deconvolution of absorption spectra (Mann \& Myers 1968 , Hoepffner \& Sathyendranath 1991). Our results are, for the most part, in accordance with these studies. Moreover, determination of in vivo weight-specific absorption coefficients for individual pigments or pigmentprotein complexes has shown to be a promising and useful technique to trace pigment-specific signatures and to model the effect of packaging on the absorption characteristics of phytoplankton (Bidigare et al. 1987 , Nelson \& Prézelin 1990). Our studies indicate that additional transformation of data and the discriminant analysis on $a_{\log }(\lambda)$ spectra together with spectral pigment fingerprinting, represented by HPLC data (Table 2), may also be useful in discriminating between species-specific absorption and in finding which sets of wavelengths are optimum for distinguishing between different phytoplankton taxa. As an example, all bloom-forming and toxic phytoplankton genera examined here have been found within or near the chl $c_{3}$ group, which in turn can be separated from other groups by the use of only 3 appropriate wavelengths $(481,535,649 \mathrm{~nm})$ if LL and HL data are grouped separately. Unfortunately, the chl $c_{3}$ group cannot be further separated into toxic and non-toxic subgroups because the optical characteristics of the species in this group examined by us were too similar.
On the basis of a study of 5 phytoplankton species, SooHoo et al. (1986) concluded that photoadaptation affects the light absorption characteristics of phytoplankton more than the species-specific pigment signature. Three of the five species examined by them were also examined here, i.e. the diatoms Thalassiosira pseudonana and Phaeodactylum tricornutum and the prymnesiophyte Pavlova lutheri. These species have a similar pigment composition and thus, light absorption characteristics, when grown under similar light conditions (Figs. 1 to 3 ). In our study, the absorption spectra of the 3 species could be separated on the basis of only 3 wavelengths. We think this demonstrates the usefulness of the transformation and scaling of spectra employed here.

Admittedly, our data are based on unialgal laboratory cultures. However, such studies represent a necessary first step if in situ multi-wavelength bio-optical data are to be interpreted in terms of species composition. The use of 5 taxonomically relevant wavelengths $(481535,586,628,649 \mathrm{~nm})$ yielded near-optimal classification success, however, 3 of these wavelengths may be inconvenient in conjunction with remote sensing of ocean colour because of the high absorption coefficients of water relative to phytoplankton at 580 to $700 \mathrm{~nm}$ (cf. Kirk 1992). This may, to some extent, impede classification on the basis of remotely based data. Our approach, presumably, will be more useful for treating data from multi-wavelength attenuation sensors suspended from buoys. If communities are small and multi-specific, identification may be difficult. Yet, the more the phytoplankton community approaches a unialgal bloom, the easier it should be to identify the group to which the predominant species belong. Our 3 to 5 wavelength approach is therefore primarily relevant during phytoplankton blooms for which knowledge of species composition (e.g. toxic vs non-toxic species) may be of practical relevance in conjunction with 'algal warning' systems developed in conjunction with aquaculture.

Acknowledgements This project was financed by a grant from the Royal Norwegian Research Council for Scientific and Industrial Research (NTNF NNMK 24095) to G.J. Thanks to Profs. Jahn Throndsen and Eystein Paasche, and Wenche Eikrem for all their help during this NTNF project and for supplying isolates of the following species: Chrysochromulina sp. A, C. leadbeateri, C. polylepis, Emiliania huxleyi, Prymnesium patelliferum, Bathycoccus prasinos, Micromonas pusilla, Pseudoscourfieldia marina, Eutreptiella gymnastica, Pseudopedinella pyriformis, Heterosigma akashiwo and Synechococcus sp. Thanks are also given to Rune Bjørgum for technical assistance and to Norman B. Nelson and Raffael V. M. Jovine for valuable suggestions during the preparation of the manuscript. Valuable comments and suggestions from 5 anonymous referees are gratefully acknowledged. Contribution no. 258 from Trondhjem Biological Station 


\section{LITERATURE CITED}

Anderson, T W. (1984). An introduction to multivariate statistical methods, 2nd edn. John Wiley, New York

Bidigare, R. R., Kennicutt, M. C. II, Ondrusek, M. E., Keller, M. D., Guillard, R. R. L. (1990a). Novel chlorophyll-related compounds in marine phytoplankton: distributions and geochemical implications. Energy Fuels 4: 653-657

Bidigare, R. R., Morrow, J. H., Kiefer, D. A. (1989a). Derivative analysis of spectral absorption by photosynthetic pigments in the western Sargasso Sea. J. mar. Res. 47: 323-341

Bidigare, R. R., Ondrusek, M. E., Morrow, J. H., Kiefer, D. A. (1990b). In vivo absorption properties of algal pigments. Ocean Optics 1302: 290-302

Bidigare, R. R., Schofield, O., Prézelin, B. B. (1989b). Influence of zeaxanthin on quantum yield of photosynthesis of Synechococcus clone WH7803 (DC2). Mar. Ecol. Prog. Ser. 56: $177-188$

Bidigare, R. R., Smith, R. C., Baker, K. S., Marra, J. (1987). Oceanic primary production estimates from measurements of spectral irradiance and pigment concentrations. Global biogeochem. Cycles 1: 171-186

Bjørnland, T., Liaaen-Jensen, S. (1989). Distribution patterns of carotenoids in relation to chromophyte phylogeny and systematics. In: Green, J. C., Leadbeater, B. S. C., Diver, W. L. (eds.) The chromophyte algae: problems and perspectives. Systematics Association Special Vol. 38. Clarendon Press, Oxford, p. 37-60

Guillard, R. R. L., Ryther, J. H. (1962). Studies of marine plankton diatoms. I. Cyclotella nana Hustedt and Detonula confervacea (Cleve) Gran. Can. J. Microbiol. 8: $229-239$

Hertzberg, S., Liaaen-Jensen, S. (1966). The carotenoids of blue-green algae. I. The carotenoids of Oscillatoria rubescens and an Athrospera sp. Phytochemistry 5: 557-563

Hoepffner, N., Sathyendranath, S. (1991). Effect of pigment composition on absorption properties of phytoplankton. Mar. Ecol. Prog. Ser. 73: 11-23

Jeffrey, S. W. (1980). Algal pigment systems. In: Falkowski, P. G. (ed.) Primary productivity in the sea. Brookhaven symposia in biology no. 31. Plenum Press, New York, p. $33-58$

Jeffrey, S. W. (1989). Chlorophyll $c$ pigments and their distribution in the chromophyte algae. In: Green, J. C., Leadbeater, B. S. C., Diver, W. L. (eds.) The chromophyte algae: problems and perspectives. Systematics Association Special Vol. No. 38. Clarendon Press, Oxford, p. 13-36

Jeffrey, S. W., Humphrey, G. F. (1975). New spectrophotometric equations for determining chlorophylls $a, b, c_{1}$ and $c_{2}$ in higher plants, algae and natural phytoplankton. Biochem. Physiol. Pfl. 167: 191-194

Johnsen, G., Sakshaug, E. (1993). Bio-optical characteristics and photoadaptive responses in the toxic and bloom-form-

This article was submitted to the editor ing dinoflagellates Gyrodinium aureolum, Gymnodinium galatheanum and two strains of Prorocentrum minimum. J. Phycol. 29: 627-642

Johnsen, G., Sakshaug, E., Vernet, M. (1992). Pigment composition, spectral characterization and photosynthetic parameters in Chrysochromulina polylepis. Mar Ecol. Prog. Ser. 83: 241-249

Kirk, J. T O. (1983). Light and photosynthesis in aquatic ecosystems. Cambridge University Press, Cambridge

Kirk, J. T. O. (1992). The nature and measurement of the light environment in the ocean. In: Falkowski, P. G., Woodhead, A. D. (eds.) Primary productivity and biogeochemical cycles in the sea. Plenum Press, New York, p. 9-30

Krzanowski, W. J. (1988). Principles of multivariate analysis. A user's perspective. Clarendon Press, Oxford

Liaaen-Jensen, S. (1978). Marine carotenoids. In: Scheuer, P. J. (ed.) Marine natural products. Chemical and biological perspectives. Academic Press, New York, p. 1-73

Mann, J. E., Myers, J. (1968). On pigments, growth, and photosynthesis of Phaeodactylum tricornutum. J. Phycol. 4: 349-355

Mantoura, R. F. C., Llewellyn, C. A. (1983). The rapid determination of algal chlorophyll and carotenoid pigments and their breakdown products in natural waters by reversephase high-pressure liquid chromatography. Analytica chim. Acta 151: 297-314

Mardia, K. V., Kent, J. T., Bibby, J. M. (1979). Multivariate analysis. Academic Press, London

Mitchell, B. G., Kiefer, D. A. (1988). Chlorophyll a specific absorption and fluorescence excitation spectra for lightlimited phytoplankton. Deep Sea Res. 35: 639-663

Nelson, N. B., Prézelin, B. B. (1990). Chromatic light effects and physiological modeling of absorption properties of Heterocapsa pygmaea (= Glenodinium sp.). Mar. Ecol. Prog. Ser. 63: $37-46$

Prézelin, B. B., Boczar, B. A. (1986). Molecular bases of cell absorption and fluorescence in phytoplankton: potential applications to studies in optical oceanography. In: Round, F. E., Chapman, D. J. (eds.) Progress in phycological research, Vol. 4. Biopress, Ltd, Bristol, p. 350-465

Rowan, K. S. (1989). Photosynthetic pigments of algae. Cambridge University Press, Cambridge

Sathyendranath, S., Lazzara, L., Prieur, L. (1987). Variations in the spectral values of specific absorption of phytoplankton. Limnol. Oceanogr. 32: 403-415

SooHoo, J. B., Kiefer, D. A., Collins, D. J., McDermid, I. S. (1986). In vivo fluorescence excitation spectra of marine phytoplankton. I. Taxonomic characteristics and responses to photoadaptation. J. Plankton Res. 8: 197-214

Straub, O. (1987). Key to carotenoids, 2nd edn. Birkhäuser Verlag, Basel

Tabachnick, B. G., Fidell, L. S. (1989). Using multivariate statistics, 2nd edn. Harper \& Row, New York

Manuscript first received: March 16, 1993

Revised version accepted: November 8, 1993 